\title{
Multiple talon cusps, dens in dente and concrescence in a child with hypomelanosis of Ito
}

\author{
Feyza Nur Gorken, Ikikarakayali Goksen, Arzu Pinar Erdem, Sinem Kuru, Elif Sepet*
}

Department of Pediatric Dentistry, Faculty of Dentistry, Istanbul University, Istanbul, Turkey

Email: *elifsepet@hotmail.com

Received 17 May 2012; revised 18 June 2012; accepted 24 June 2012

\begin{abstract}
Hypomelanosis of Ito (HI) is a rare neurocutaneous disorder most likely caused by chromosomal mosaicism. HI patients may suffer from numerous clinical manifestations, but the expression of the disease is highly variable. Ophthalmologic, musculoskeletal, neurologic, and dental anomalies may be associated with the syndrome. The dental abnormalities found in HI include talon cusps, a single maxillary central incisor, enamel defects, hypodontia, and irregularly spaced teeth. The aim of this case report is to present multiple talon cusps, dens in dente and concrescence of maxillary permanent incisors in an 8-year-old boy affected with hypomelanosis of Ito. This unusual dental anomaly has been described in two previous reports of this neurocutaneous syndrome. HI can be difficult to diagnose, these dental findings may help to identify the syndrome in cases where other findings are minimal or atypical.
\end{abstract}

Keywords: Hypomelanosis of Ito; Incontinentia Pigmenti Achromians; Talon Cusps

\section{INTRODUCTION}

Hypomelanosis of Ito (HI) is a syndrome with hypopigmented whorls of skin along the Blaschko lines. The old name, incontinentia pigmenti achromians, implies an association with incontinentia pigmenti (IP) and was probably used because hypomelanosis of Ito appears to be the negative image of incontinentia pigmenti. This name was found to be incorrect. Ito first described the syndrome in 1952, with only cutaneous findings. The hypopigmentation is not preceded by vesicular or verrucous lesions. This feature is in contrast to the usual presentation of incontinentia pigmenti. Reports soon followed, with description of multiple other congenital defects, mostly neurologic, skeletal, hair, and dental findings [1].

Although HI is often considered the fourth most com-

*Corresponding author. mon neurocutaneous syndrome, its incidence is very rare. Hypomelanosis of Ito is 1.5 - 2.5 times more common in females than in males. Chromosomal mosaicism is believed to be the reason that hypomelanosis of Ito is so varied in phenotype. Certain genes, namely, those on 9q33-qter, 15q11-q13, and Xp11, have been implicated in hypomelanosis of Ito; however, no consensus exists about the identity of the hypomelanosis of Ito gene [2].

\subsection{Diagnosis}

The diagnosis is made in most individuals within the first year of life because of the hypopigmentation of their skin. As in tuberous sclerosis, early diagnosis is enhanced by using a Wood's lamp when evaluating children with new onset seizures; the bilateral or unilateral hypopigmented whorls, streaks, and patches are usually found on the trunk and limbs. These lesions follow the lines of Blaschko, swirling around the trunk and down the arms or legs. HI can be difficult to diagnose but careful examination can differentiate it from similar disorders, such as incontinentia pigmenti, tuberous sclerosis, nevus depigmentosus and vitiligo [3].

\subsection{Clinical Features}

All affected individuals have the hypopigmented skin lesions. A significant number of affected individuals also show CNS involvement, most frequently mental retardation and seizures. Other significant neurologic complications included hypotonia, macrocephaly, microcephaly, speech delay, autistic behaviors, and expressive language disabilities. Skin manifestations include café-au-lait spots, cutis marmorata, angiomatous nevi, nevus of Ota, Mongolian blue spots, hypohidrosis of hypopigmented areas, and morphea. Hair, tooth, and nail abnormalities can also be seen. Ophthalmologic abnormalities include strabismus, nystagmus, congenital cataracts, and various other nonspecific findings. A number of dental and craniofacial abnormalities can be seen. Some patients have limb asymmetries, scoliosis, pectus anomalies, and foot 
deformities. Cardiac, kidney, liver, and genital abnormalities, as well as benign and malignant tumors, have also been reported to a lesser extent [1,3].

\subsection{Treatment}

Treatment for HI is symptomatic. The skin lesions require no special treatment, and individuals do not have to take extra precautions with sun exposure. For individuals without additional neurologic manifestations, an annual follow-up appointment is recommended. The hypopigmented lesions tend to darken with time. Children with $\mathrm{HI}$ and neurologic complications will benefit from special education services. Surgery, corrective glasses, vision therapy, and medication may help some of the ophthalmologic conditions seen in HI. Patients suffering from seizures may benefit from antiepileptic drugs [3].

$\mathrm{HI}$ also may have associated dental anomalies, but only a few reports have been published. Browne and Byrne (1976) reported on an unusual form of dental dysplasia and the microscopic structure of the teeth in HI [4]. Happle and Vakilzadeh (1982) reported multiple dental cusps in both primary and permanent incisors [5]. Bartholomew et al. (1987) reported congenital absence of a maxillary primary central incisor [6]. Tsutsumi and Oguchi (1991) reported a labial talon cusp in a child with incontinentia pigmenti achromians [7]. Kumar and $\mathrm{Ku}-$ riakose (2001) reported hypoplastic teeth and tongue abnormalities in HI [8]. This paper describes a patient with $\mathrm{HI}$ having multiple talon cusps, dens in dente and concrescence of maxillary permanent central incisors, which have not previously been reported together.

\section{CASE REPORT}

An eight-year-old male patient presented with the chief complaint of abnormally shaped maxillary permanent central incisor.

The patient's in utero course and delivery were uneventful. At birth, areas of pigmentation and depigmentation were present on the child's trunk and extremities without inflammation. Developmental delay, autism, eye, skin and nail involvements were present in the patient [Figure 1]. Family history was negative for HI. The patient was referred to the Departments of Dermatology and Child Neurology, Istanbul University, Faculty of Medicine at 3 years of age, and was diagnosed with HI.

Oral examination revealed abnormally shaped and partially erupted maxillary permanent central incisors [Figure 2(a)].The primary lower incisors were widely spaced and conical in shape [Figure 2(b)]. The radiographic examination revealed multiple dental cusps of the maxillary permanent central incisors. The maxillary left permanent central incisor exhibited a well-defined three cusps. The cusps composed of normal enamel and dentin, and contained pulp horns. The maxillary right permanent central incisor exhibited a well-defined two cusps with normal enamel, dentin and contained pulp horns .The cusps were identified as Type I talon cusps. The tooth also exhibited dens in dente and concrescence of a supernumerary tooth [Figure 3]. The gingiva, tongue, and oral mucosa were normal in color, contour and texture. The primary lower central incisors were extracted under local anesthesia. After totally eruption of maxillary per- manent central incisors, the teeth were treated under general anesthesia [Figures 4 and 5] Due to space and esthetic problems the teeth were reduced in size. Root canal therapy was performed to maxillary left incisor and composite restorations were performed in both teeth.

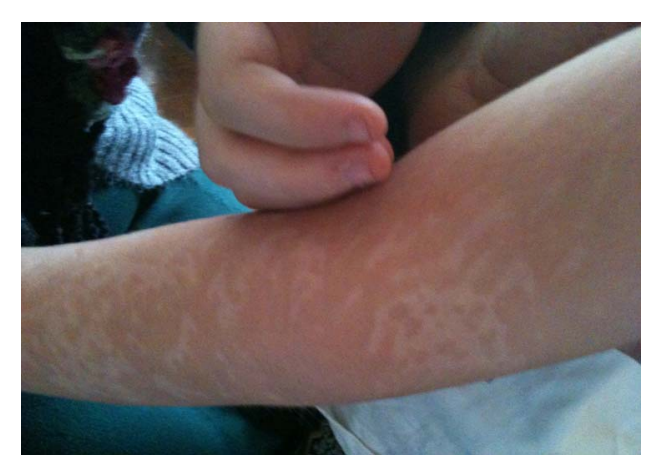

Figure 1. Skin and nail involvements were present in the patient.

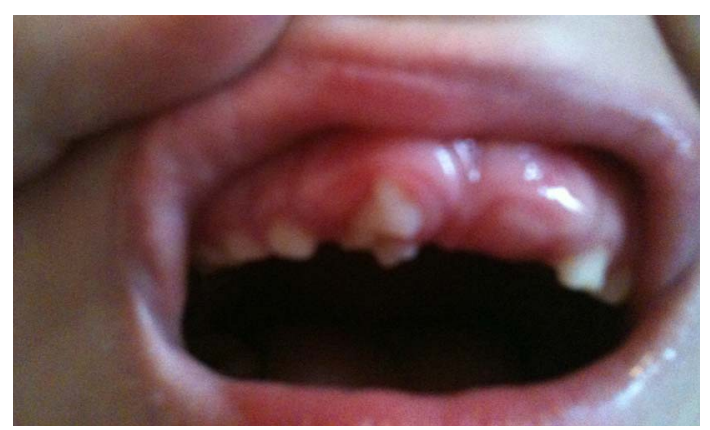

(a)

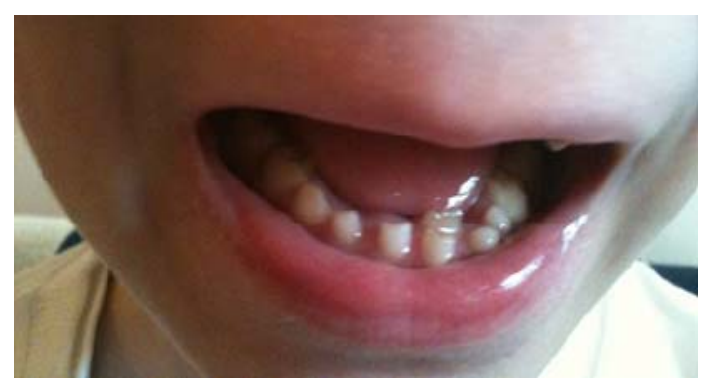

(b)

Figure 2. Abnormally shaped and partially erupted maxillary permanent central incisors (a). Widely spaced and conical primary lower incisors (b). 


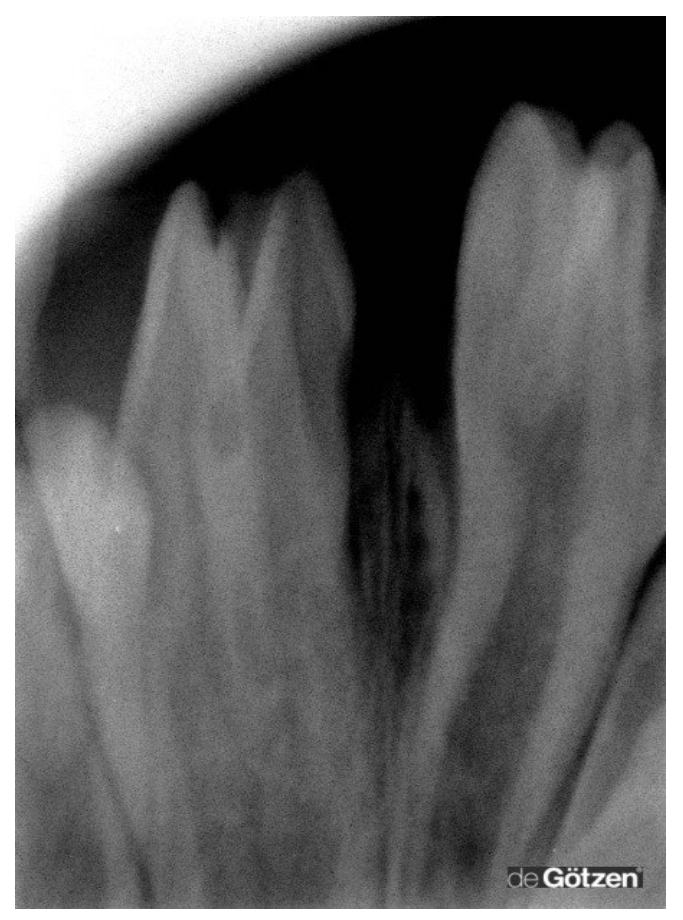

Figure 3. Well-defined multiple talon cusps composed of enamel and dentin, and contained pulp horns in both central incisors. The left incisors also exhibited dens in dente and concrescence of a supernumerary tooth.

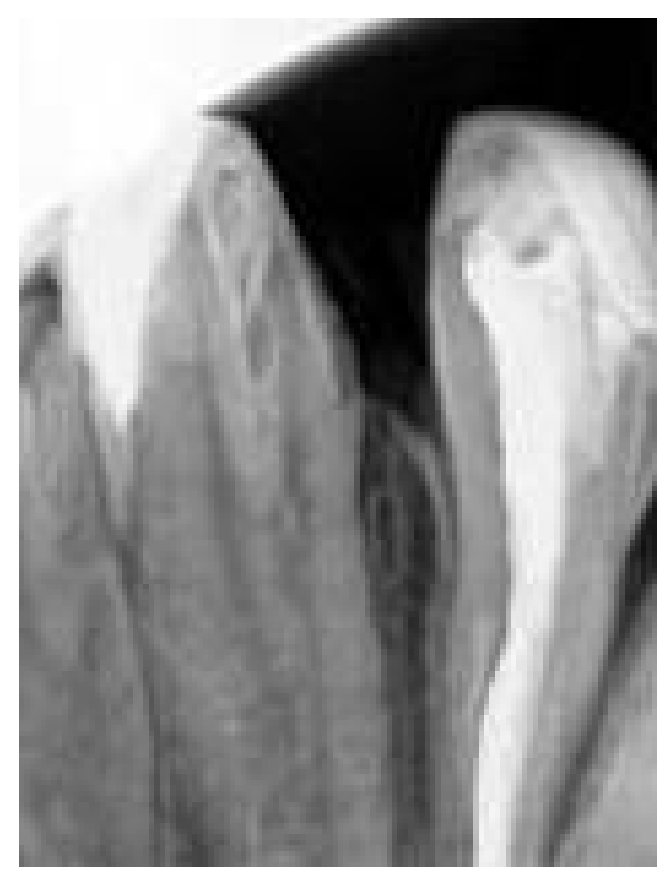

Figure 4. The teeth were reduced in size; root canal therapy was performed to maxillary left incisor and composite restorations were performed to overcome esthetic, occlusal, periodontal and carious problems. Mineral trioxide aggregate was used as direct pulp capping material in maxillary right incisor.

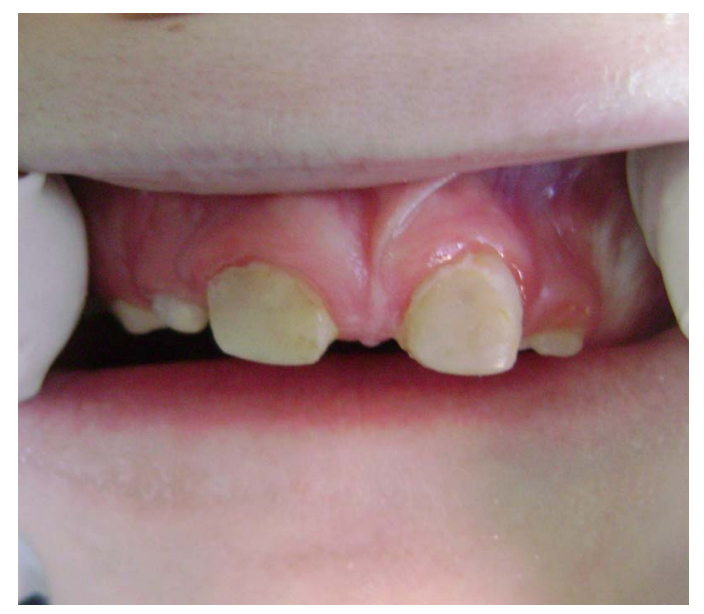

Figure 5. Post-operative view of restored incisors.

\section{DISCUSSION}

Dermatologic diseases and syndromes are often diagnosed through the identification of systemic signs and symptoms. Dental pathology is seen in a range of dermatologic disorders. The specific dental signs associated with cutaneous diseases can aid in the diagnosis of patients.

We report an 8-year-old male patient with $\mathrm{HI}$ having multiple talon cusps, dens in dente and concrescence of maxillary permanent central incisors. The endodonticrestorative treatments of teeth are also presented. The esthetic and functional needs of individuals affected with this disease are high and various treatment options are available.

The accessory cusp-like structure, talon cusp, originnates from disturbances in the morphodifferentiation stage of tooth development, as does any other anomaly in the size or shape of the tooth. The real cause of this condition is still unknown, but genetic and environmental factors are thought to be involved in the etiology [9].

The talon cusp may cause clinical problems related to caries or occlusal interferences. Talon cusp on the occlusal surface is subjected to direct occlusal forces, causing attrition or fracture at a much higher rate than the talon cusp on lingual surface [10].

Early diagnosis and treatment of talon cusps is strongly recommended. Treatment objectives for talon cusps are aimed at the management of deep caries-susceptible pits and fissures, occlusal interferences, esthetic problems, soft tissue irritation, interference with the tongue space, and pulpal involvement. The treatment options for the mentioned problems are dependent upon the presence of a pulp horn in the cusp and include: placement of pit-andfissure sealants or restorations, periodic gradual occlusal grinding, root canal therapy and extractions [9].

Dens in dente results from the invagination of the affected tooth crown before the mineralization. It is usually 
detected in routine radiographs. Dealing with dens in dente is challenging in clinic as it may cause pulp necrosis or periapical lesions due to the communication with the oral cavity and influx of the irritants to the pulp [11].

The treatment objectives for taloned teeth may differ depending on each case. In this case, the teeth were treated under general anesthesia. Root canal therapy was performed to maxillary left incisor and composite restorations were performed to overcome esthetic, occlusal, periodontal and carious problems.

The rare case which is presented here added other dental signs in literature such as; multiple talon cusps, dens in dente and concrescence of a supernumerary tooth associated with $\mathrm{HI}$.

HI can be difficult to diagnose, these talon cusps and other dental signs may help to identify the syndrome in cases where other findings are minimal or atypical.

\section{ACKNOWLEDGEMENTS}

The authors don't have any actual or potential conflict of interest including any financial, personal or other relationships with other people or organizations of the submitted work entitled "Multiple talon cusps, dens in dente and concrescence in a child with Hypomelanosis of Ito".

\section{REFERENCES}

[1] Nehal, K.S., PeBenito, R. and Orlow, S.J. (1996) Analysis of 54 cases of hypopigmentation and hyperpigmentation along the lines of Blaschko. Archives of Dermatology, 132, 1167-1170. doi:10.1001/archderm.1996.03890340027005

[2] Gupta, S., Shah, S., Mcgaw, A., Mercado, T., Zaslav, A.L. and Tegay, D. (2007) Trisomy 2 mosaicism in hypome- lanosis of Ito. American Journal of Medical Genetics Part A, 143A, 2466-2468. doi:10.1002/ajmg.a.31940

[3] Olson, L.L. and Maria, B.L. (2005) Hypomelanosis of Ito. In: Maria, B.L. Ed., Current Management in Child Neurology, 3rd Edition, BC Decker, Inc., London, 476-478.

[4] Browne, R.M. and Byrne, J.P.H. (1976) Dental dysplasia in incontinentia pigmenti achromians (Ito): An unusual form. British Dental Journal, 140, 211-214. doi:10.1038/sj.bdj.4803735

[5] Happle, R. and Vakilzadeh, F. (1982) Hamartomatous dental cusps in hypomelanosis of Ito. Clinical Genetics, 21, 65-68. doi:10.1111/j.1399-0004.1982.tb02081.x

[6] Bartholomew, D.W., Jabs, E.W., Levin, L.S. and Ribovich, R. (1987) Single maxillary central incisor and coloboma in hypomelanosis of Ito. Clinical Genetics, 32, 370-373.

[7] Tsutsumi, T. and Oguchi, H. (1991) Labial talon cusp in a child with incontinentia pigmenti achromians: Case report. Pediatric Dentistry, 13, 236-237.

[8] Kumar, A. and Kuriakose, S. (2001) Incontinentia pigmentii acromians with seizure disorder: A case report. Journal of the Indian Society of Pedodontics and Preventive Dentistry, 19, 145-147.

[9] Yoon, R.K. and Chussid, S. (2007) Dental management of a talon cusp on a primary incisor. Pediatric Dentistry, 29, 51-55.

[10] Al-Omari, M.A., Hattab, F.N., Darwazeh, A.M. and Dummer, P.M. (1999) Clinical problems associated with unusual cases of talon cusp. International Endodontic Journal, 32, 183-190. doi:10.1046/j.1365-2591.1999.00212.x

[11] Steffen, H. and Splieth, C. (2005) Conventional treatment of dens invaginatus in maxillary lateral incisor with sinus tract: One year follow-up. Journal of Endodontics, 31, 130-133. doi:10.1097/01.don.0000137637.94281.82 